\title{
The Social Dynamics of People Cooperation: A Study on On-line Knowledge Construction Networks
}

\author{
TSUNG-XIAN LIN ${ }^{1}$; HSIU-YUEH LIN²* $\quad$ YAN-HUI HE³ $;$ YUXIA DU ${ }^{4}$ \\ Business Administration Dept; Huashang College Guangdong University of Finance \& Economic; No1, \\ Zengcheng Avenue, Zengcheng District, Guangzho, CHINA ${ }^{1234}$
}

\begin{abstract}
A classic question common to social sciences revolves around how people cooperate. Indeed, under what conditions will cooperation emerge without central authority? However, as the complication of community is growing, the importance of answering this question is increasing. That's because the spread of mass collaboration has changed everything, such as Wikinomics. Questions posted about how networks connect individuals through structure and process, what rules and resources situate them in larger social systems, and affect the interaction to and from them. This paper concerns that why people are willing to cooperate without the aid of a central authority and how behavior and norms are affected by social relations. But the answer for people developing cooperation has a fundamental effect on social, political, and economic relations with others. Because of the social phenomena is composed of action, interaction, and relationship through network structure, analysts should not discrete individual behavior and ongoing network structure. As central objectives of network analysis are to measure and represent structural and to explain both why they occur and what are their consequences. The approach of this study is to propose network analysis to explain how participator actions for the cloud aid education in China. The aim of this study is to utilize network diagram to analyze network structure of the cloud aid education. Based on longitudinal study, we offer a structural means to understand how knowledge creation and sharing occurs within networks, and then find the key determinants of efficient knowledge management. Mapping these dimensions in social networks enable social and technical interventions managers can employ to improve a network's ability to create and share knowledge. The result is illustrated by investigating conditions of cooperation and identifying social
\end{abstract}

Key-Words: Social Influence, Social Network, Network Analysis, Mass Collaboration.

Received: March 10, 2020. Revised: July 24, 2020. Accepted: August 2, 2020. Published: August 10, 2020

\section{Introduction}

With a vast territory, China sees a rapid economic growth in its eastern coastal areas but a relatively backward situation in its western regions. Likely, its educational resources are not evenly distributed, with marked disparity between the eastern and western regions. In the quantitative research on the balanced distribution of basic public educational resources, Xie Rong found that Jiangsu, Zhejiang, Beijing and the three provinces in the northeast of China had the largest proportion of excellent teachers across the nation while Henan, Guangdong, Guizhou, and Yunnan had the smallest proportion ${ }^{[1]}$. In particular, Guangdong was the only province with the smallest proportion among the eastern provinces, as shown in Table 1.1.

The cloud aid education is designed to provide free aid education services for the schools with inadequate educational resources in remote areas and promote the equity of educational opportunities between rural and urban areas.

\footnotetext{
*Corresponding author

E-mail: 539300238@qq.com Tel: +8615989785298
}

Table 1.1 Basic public education resource allocation(east)

\begin{tabular}{|c|c|c|c|c|c|c|c|c|c|c|}
\hline \multirow[b]{2}{*}{ Area } & \multirow[b]{2}{*}{ Province } & \multirow{2}{*}{$\begin{array}{l}\text { Total } \\
\text { Theil } \\
\text { index }\end{array}$} & \multicolumn{4}{|c|}{ Index } & \multicolumn{2}{|c|}{$\begin{array}{l}\text { School } \\
\text { section }\end{array}$} & \multicolumn{2}{|c|}{ area } \\
\hline & & & Faculty & $\begin{array}{l}\text { Teaching } \\
\text { condition }\end{array}$ & \begin{tabular}{|c|} 
choor \\
building \\
stauss
\end{tabular} & Funding & $\begin{array}{c}\text { primary } \\
\text { school }\end{array}$ & \begin{tabular}{|c|} 
Junior \\
high \\
school \\
\end{tabular} & Town & $\begin{array}{c}\text { Rural } \\
\text { arca }\end{array}$ \\
\hline \multirow{11}{*}{ east } & Jiangsu & 0.31 & 0.06 & 0.15 & 0.04 & 0.06 & 0.31 & 0.32 & 0.38 & 0.30 \\
\hline & Shanghai & 0.23 & 0.02 & 0.14 & 0.01 & 0.06 & 0.21 & 0.32 & 0.36 & 0.09 \\
\hline & \begin{tabular}{|l|} 
Zhejiang \\
\end{tabular} & 0.23 & 0.04 & 0.10 & 0.03 & 0.06 & 0.21 & 0.25 & 0.27 & 0.26 \\
\hline & Beijing & 0.22 & 0.05 & 0.08 & 0.01 & 0.09 & 0.26 & 0.32 & 0.29 & 0.19 \\
\hline & Liaoning & 0.11 & 0.04 & 0.05 & 0.01 & 0.02 & 0.09 & 0.23 & 0.14 & 0.13 \\
\hline & Shandong & 0.09 & 0.05 & .03 & 0.01 & 0.00 & 0.06 & 0.13 & 0.10 & 0.13 \\
\hline & Tianjin & 0.07 & 0.02 & 0.01 & 0.00 & 0.03 & 0.07 & 0.10 & 0.09 & 0.05 \\
\hline & Guangdong & 0.06 & \begin{tabular}{|l|}
-0.03 \\
\end{tabular} & 0.08 & 0.02 & -0.01 & 0.16 & -0.04 & 0.18 & -0.01 \\
\hline & Fujian & 0.06 & 0.01 & 0.02 & 0.01 & 0.01 & 0.08 & 0.02 & 0.02 & 0.14 \\
\hline & Hebei & 0.05 & 0.02 & 0.04 & 0.00 & -0.01 & 0.04 & 0.05 & 0.02 & 0.15 \\
\hline & Hainan & 0.00 & 0.00 & 0.00 & 0.00 & 0.00 & 0.01 & -0.01 & -0.01 & 0.02 \\
\hline
\end{tabular}

The cloud aid education model can offer education regardless of spatial distance and save much time. With this model, college volunteers can offer aid education and reward society without traveling to rural areas. Besides, they can take initiative to care about those who are in need of help, especially primary and secondary school students, and share their thoughts, study and achieve personal growth together in daily life. According to the statistics released by iResearch Consulting, the Chinese market of online education reached RMB 68.06 billion in 2018, with a year-on-year increase of 
25.7\%; there were 135 million Chinese users of online education in the same year, with a year-onyear increase of $23.3 \%$. As of March 2020, the number of online education users has reached 423 million, an increase of $110.2 \%$ from the end of 2018 , accounting for $46.8 \%$ of the total netizens. 20172020 online education growth show in Figure 1.1.

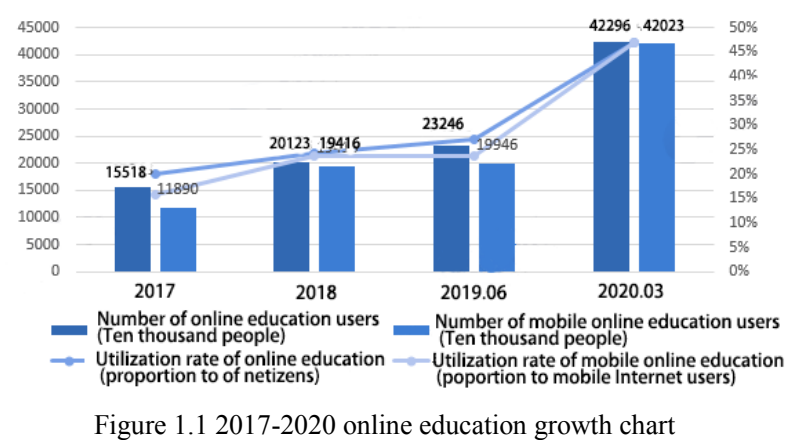

Compared with the traditional aid education, the cloud aid education has a tremendous advantage giving a greater number of people a better access to aid education and thus solving the problem of inadequate aid education givers in reality. The coronavirus epidemic has changed the way people interact with each other and stepped up the transition from the tradition education to online education.

From a rational perspective, individual actions are determined by self-interest and maximization of utility, but why is there a large pool of "free labor" contributing towards a common goal? Furthermore, from an economic perspective, why is each member of the group foregoing the tendency to be a "free rider" in global free platforms such as open source software development? A classic answer to explain how people develop cooperation revolves around the fundamental effects of social, political, and economic relations individually. However, through the popularity of Internet and World Wide Web, global collaboration has a more dynamic complexity and is more difficult to predict. There are rarely any comprehensive studies to realize the puzzle of crowdsourcing; in particular, the interplay between information science of each other is lacking.

Coleman argued that a theoretical development in social action is better in conjunction with the principles of rational or purposive action and the particular social contexts that affect the structure of the group network, both internally and externally ${ }^{[2]}$. Because a social phenomenon is composed of action, interaction, and relationship through a network structure, Wellman \& Berkowitz suggested that social networks analysis is better for studying social phenomena that links "micro" networks of interpersonal relations with "macro" structures in large-scale social systems ${ }^{[3]}$.

\section{Literature Review}

The collaboratively edited encyclopedia Wikipedia or open-source software projects connect individual action, interaction, and social structure to form a new kind of collaboration ${ }^{[4]}$. Despite mass collaboration through digital platforms being able to easily connect with each other to deal with complex processes and tasks ${ }^{[5]}$, the top concern begs the question behind why people participate in such efforts for sustained periods of time ${ }^{[6]}$. In addition, actors' behaviors are embedded in ongoing systems of social relation ${ }^{[7]}$, thus collaborative actions have been remarkably causing major transformations in economic and social activity worldwide. Building on the above definition, we examine relevant theories applied in individual actions and cooperative network to guide comprehensive interpretation on the issue of mass collaboration.

A virtual team can organize a group of people who may be physically far away from each other and break temporal and spatial limitations. Through coordination and collaboration, they strive to fulfill common objectives. Besides, an efficient virtual team is usually able to adapt itself to the technologies it uses and its members can become interconnected to finish tasks ${ }^{[8]}$.

\subsection{Individual Motivations}

The aspect that individuals are purposeful and goal directed is widely accepted. Similarly, Coleman pointed that human behaviors are guided by interest, benefits and constraints within the social environment ${ }^{[9]}$. An agreement on the observation of Scacchi, the reasons for contributors within open source software development are not only looking for personal or professional career, but also believing the value behind the free software ${ }^{[6]}$.

Individuals would analyze the costs and benefits before they act to cooperate with others, so purposive action requires information whatever from personal measurement or cooperative structure; furthermore, an asymmetry of information would lead to increased asymmetries power between corporate actors and persons ${ }^{[2]}$. More noteworthy is that World Wide Web popularization decreases the degrees of connections between actors in social network, thus information travels from one point to any other point with apparently only a handful of steps in between ${ }^{[10]}$. When highly informed actual others doing by drawing public attention, the desirable or undesirable behaviors can be increased $^{[11]}$.

\subsection{Structure Embeddeness}


Individual participation in electronic social networks is a form of collective action, further, collaboration is the processes of actors' interactions for exchanging relationships ${ }^{[6]}$. Social capital is intangible resource consisted of information flows among individual or corporate behavior, there are three forms of social capital: obligation and expectations, information channels, and social norms $^{[2]}$.

Tapscott and William concluded the self-organizing workplace where millions of people participate in required five functions: (1) Free and diverse team; (2) Allocation of personal time; (3) Decision making oriented; (4) Allocation of independent resources; and (5) Corporate communications ${ }^{[5]}$. More noteworthy is that continuity of relationships to form social system can generate behavior by the quick spread of information ${ }^{[7]}$.

\subsection{Social Mechanisms}

Granovetter argued that actors do not behave or decide outside a social context ${ }^{[7]}$. People are sensitive to the opinions of others, hence social influence is an external force shaping individuals' actions into similar way within ongoing social relations and structures ${ }^{[7]}$. As discussed in Scacchi, a freely collaborative platform where thousands of individuals engage in is highly dynamic community ${ }^{[6]}$, such as crowdsourcing. Refer to the examination of Coleman, conditions of economic activity is organized in different institutional forms, so as the collaborative network possess to shape, reshape, configure, and reconfigure individual actions to escape the free-rider circumstances ${ }^{[2]}$.

In summary, the research adopts the suggestion of Coleman work ${ }^{[2]}$. The theoretical framework is built around a fundamental conception of sociology and economics, and a discussion of information technology as vehicles for mass collaboration. It explains the principle of rational action, collective behavior guided by the structural embeddeness, and individual's action is shaped, constrained, and redirected by the social context, so-called nonrationality behavior.

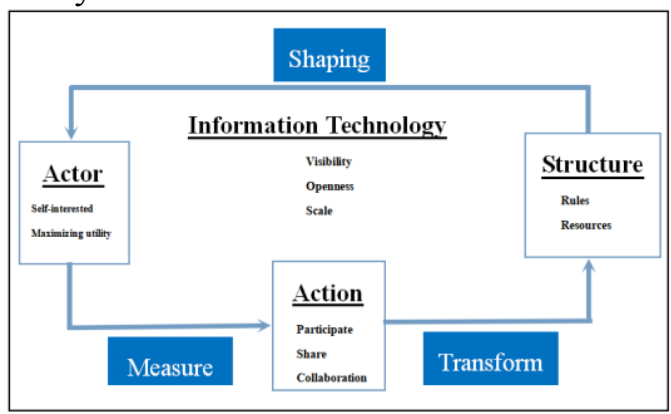

Figure 2- 1. From Micro to Macro: The Process of Mass Collaboration

Collaboration that technology in and of itself is particularly influential exchange motivates and enhances social context to effect exchange process ${ }^{[12]}$. So, our objective in the framework is to focus on socio-economic-technological elements in mass collaboration. Figure 2-1 presents the framework of our perspective of mass collaboration.

\section{Case Study}

This is an exploratory study which first reviewed relevant literature and defined the direction, value, feasibility and rationality of the research. Then, a questionnaire survey was conducted to gather objective data. In-depth interviews were undertaken to obtain the basic data about the operation performance of the virtual teams of college volunteers. After that, the figures processed with a piece of social network analysis software were combined with the data for illustration. Finally, key members were induced through a social network analysis, with the hope of exploring an effective operation model for the virtual teams of college volunteers and offering some useful information about organizational operation to college volunteer teams.

The details about the cloud aid education propelled by a college volunteer team are shown in Figure 3-1. Cloud aid education involves providing free aid education to the western regions which lacks sufficient educational resources through online interactive teaching; it expresses the concept of the internet-based poverty alleviation. In 2008, cloud aid education was spontaneously launched by a group of college students who were passionate about public interest. With the principle of enhancing the equity of educational opportunities between rural and urban areas, it can offer education regardless of spatial distance and save much time. With cloud aid education, college volunteers can offer aid education and reward society without traveling to rural areas.

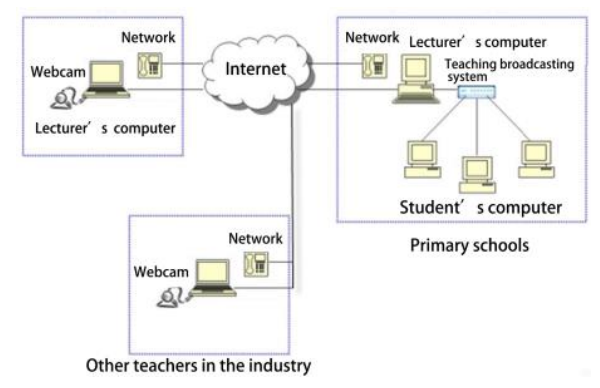

Figure 3-1 The cloud aid education support structure

The first teaching base of cloud aid education is Zhuhai Campus, Jinan University. To date, there have been five teaching bases, with the volunteers from five campuses of two colleges -- Jinan 
University (JNU) and Huashang College for Guangdong University of Finance \& Economics (GUFE) that are located in Zhuhai, Guangzhou, Zengcheng and Shenzhen. In addition, many figures from Taiwanese enterprises and schools have joined the cloud aid education team.

As Jinan University is a renowned university for overseas Chinese, the cloud aid education can integrate the resources and experience from Guangdong, Hong Kong, Macao and Taiwan with humanistic concern (see Figure3-2).

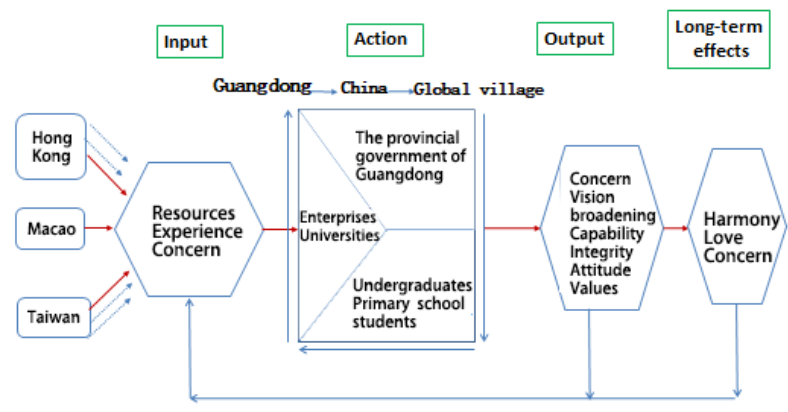

Figure 3-2 The cloud aid education resource integration

If the provincial government of Guangdong and the universities in the province call on the undergraduates to participate in the cloud aid education, the teacher resources of the province will be swiftly and efficiently enriched.

\subsection{Study Data}

Starting in March 2019, this study conducted a questionnaire and in-depth interviews, involving the volunteers from JNU and GUFE as well as the principals, directors and instructors from the partner primary schools. The interviews were completed in November 2019, lasting for nine months. The partner primary schools are as follows Table 3.1:

Table 3.1 List of interviewed primary schools

\begin{tabular}{llll}
\hline Primary School & Province & Primary School & Province \\
\hline \multicolumn{1}{c}{ Nanshan } & Guangdong & Hengshan & Guangdong \\
Dongjing & Guangxi & Nancun & Guangdong \\
Xingguang & Gansu & Lulian & Guangdong \\
Xidong & Gansu & Ximazhen & Guizhou \\
Nanfeng & Guangdong & Xianshui & Guizhou \\
Suzhan & Gansu & Yuduzhen & Jiangxi \\
Yifu & Guangxi & Longma & Guangdong \\
Zhonghua & Guizhou & Fanxiang & Jiangxi \\
\hline
\end{tabular}

\subsection{Result}

From the perspective of system integrity, this study adopted the observation based on the collective network expansion and the network analysis software UCINET6.0 $0^{[13]}$ to obtain the numerical values for assessment and analysis. Besides, the contents of the interviews were sorted out to find out the key factors of the successful operation of a virtual team.
The social network theory takes the whole network as the core, and the relational networks constituted by all the members within a specific scope are taken as the foundation of analysis and explanation. Focus is placed on the interpersonal interaction in networks and the control of different positions in a network on resources. Social network consists of three elements: (1) nodes, or actors, (2) relationship between actors and (3) Tie, or the path through which actors are connected.

\subsubsection{Network analysis of the college volunteer team}

In a globalized business environment, the operating form of a virtual team has become an attractive management strategy. The main reason is that it allows decentralized organizations to maximize their respective expertise without worrying about substantial individual physical flow.

A virtual team is a group of people interacting on a task based on a common goal. The difference from a traditional team is that it uses the communication technology network to connect and can work together across time and space and organizations.

1. Overall network figure of the college volunteer team

The college volunteer team was small at its founding, and its interactive collaboration was by two groups of people. The first was the information group of the official website of the cloud aid education, whose aim was to establish new websites and modify existing ones. The number of the group members was small, but the interaction and collaboration among them were efficient. The second group comprised college volunteers, all of whom were from the universities in Guangzhou, and the interaction among them was good.

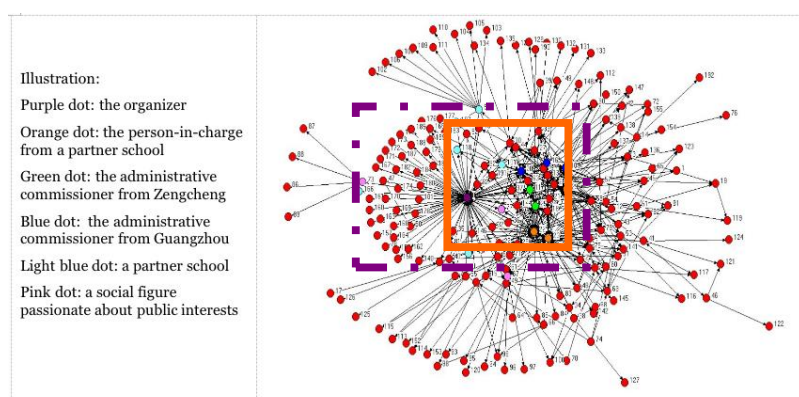

Figure3-3 Overall network figure of the college volunteer team

But the follow-up observation showed that the majority of them left the group and only a few stayed and worked as a lecturer. When asked for the reason, the person in charge of the team explained that the campus network access for the platform was so slow that the online class was not smooth and the interaction and connection among the volunteers were also affected. Consequently, the passion of the 
volunteers faded, and they quit. The current team is the result of years of accumulation. The overall network figure is shown in Figure 3-3.

There are 192 nodes and 572 ties in Figure 3-3. The orange solid line reveals that the internal collaboration was rather frequent, and the communication with the partner schools was smooth. No.166 (Shaw Primary School) had not interacted with the team because the construction of its school buildings had not been completed. Hence, efforts can be made for the interaction after the construction is done. The purple dotted line shows that the organizer was the most important figure of the team. The connections on the left were external ones, and most of them were one-way ones. The ones on the right were internal ones, and they were two-way ones with good collaboration.

2. Overall two-way interaction of the college volunteer team

If an individual human capital is taken as a node and the interaction between individual human capitals is considered as a tie between nodes, the network consisting of the nodes and ties will be an interhuman capital relational network, and the structural capital of the organization will be regarded as the ability to connect individual human capitals.

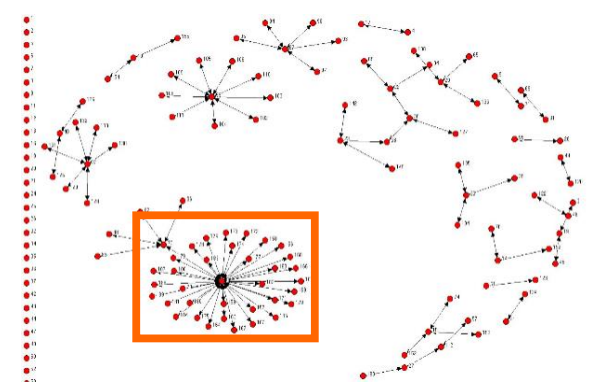

Figure 3-4 Overall two-way interaction of the college volunteer team

There was a remarkable contrast between the left and right sides of Figure 3-4, which showed the interaction and collaboration inside and outside the team. The interaction between the inside and the outside was obviously inadequate and needs to be strengthened by the college volunteer team. The orange solid line reveals that the key figures of the social network were No.0, No.22, No.23, No.29, No.10, No.16 and No.20. Taking the essential position as an intermediary, they had more information and imposed noticeable effects on their teams. As a whole, an equivalent and balanced collaborative relationship has not been established, and special attention must be paid to this problem in the future. According to the figure, the organizer attracted more volunteers, and most of these volunteers were new ones; besides, many collaborative groups served the same partner school, but each group was able to operate separately and shared experience internally. The collaborative teams were guided by elder fellow students who passed on practical experience in teaching. This is a phenomenon worthy of attention.

\subsubsection{Analysis of the relational network of the college volunteer team}

20th century introduced a variety of new technologies and innovations that certainly changed not only the means and methods of production but also management methods ${ }^{[14]}$. Interpersonal interaction is a process, where an individual would evaluate others' behaviors and then exchange valuable resources. Based on the social exchange theory that participators would exchange resources with each other in activities within their communities, and only with appealing resources would both parties continue the interaction; as time passed, both parties would make promises to show the reliability of the relationship between them. The relational network analysis mainly involves the analysis of three types of relations: common interaction, relation between unity and network cluster, and the collaboration between members.

1. Interaction of the college volunteer team

The density of interaction, common values and task objectives, and the intensity of interaction were observed respectively. We believed that a social system with the strongest unity featured a connection among all members and a close interaction; a team's unity was highly correlated to its performance, and a team with enormous unity would find it easier to fulfill its goals.

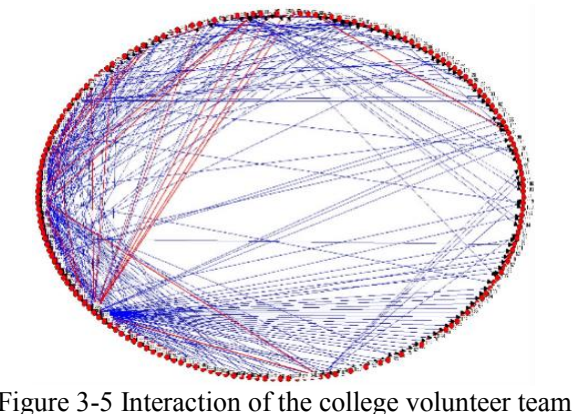

Figure 3-5 shows the interaction of the college volunteer team. The red lines have a two-way arrow, which indicates both parties nominated each other and that the volunteers interacted and collaborated with each other. The blue lines have a one-way arrow, which means that there was one-way nomination and that there was no interaction and the mechanism of mutual trust was not well-developed and the cooperation needed to be enhanced. According to the figure revealing the interaction of the college volunteer team, the number of the red 
line indicating two-way nomination was small, which manifests that the collaboration mechanism was not developed or stable enough. The data of the interviews show that the inadequate interaction was caused by the short history of the team because the volunteers had to finish their study within four years. As a result, much needs to be done to enhance the communication, trust and cooperation among the members and improve the mechanism for experience accumulation.

\section{Relational unity of the college volunteer team}

Two individuals would not interact with and nominate each other unless a close connection between them is formed. When network memory is in a reciprocal mechanism of sharing, it contributes to effective collaboration and great unity, as well as an interactive and sharing-based social network, which leads to maximum work efficiency and even determines the future of an organization.

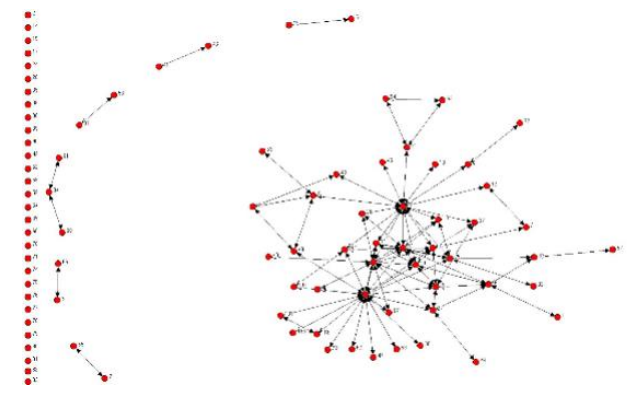

Figure 3-6 Relational unity of the college volunteer team

Figure 3-6 reveals the relational unity of the college volunteer team. The orange solid lines indicate effective interaction and collaboration, and the members were either administrative cores or the members of a teaching team. The data of the interviews show that cloud aid education was a learning platform for college students, which emphasizes "learn by doing", and the volunteers must train themselves effectively before shouldering any teaching tasks. The paired interaction beyond the orange lines came from new team members who were passionate to form a teaching team. The purple dotted lines on the left side of Figure 3-4 mean that the volunteers either nominated others or were nominated. As is shown in the data of the interviews, the formers were mainly new team members who had not participated in many activities and thus had not known many experienced volunteers. In the future, more activities must be held to ignite their passion; the latter was largely the volunteers who had not been interviewed or who refused to receive the interviews. Of these volunteers, No.144 was a key figure in the early days when the website was established, but he later left the team and refused to receive the interview.
This was a special case worthy of further exploration; otherwise, a key role would vanish unknowingly. It is the information and the knowledge acquired with its help that have become the main resource of the new modern society ${ }^{[14-16]}$

\section{Network cliques of the college volunteer team}

The network map of the two-way relations of the college volunteer team can be used for a further analysis of the network cliques, a group of actors with the strongest relation in the network. Each one of the cliques has a two-way connection. If more actors are added into this strong relation, it will influence the original relation. Cloud aid education has four network cliques, as is shown in Table 3.2.

Table 3.2 Network cliques of the college volunteer team

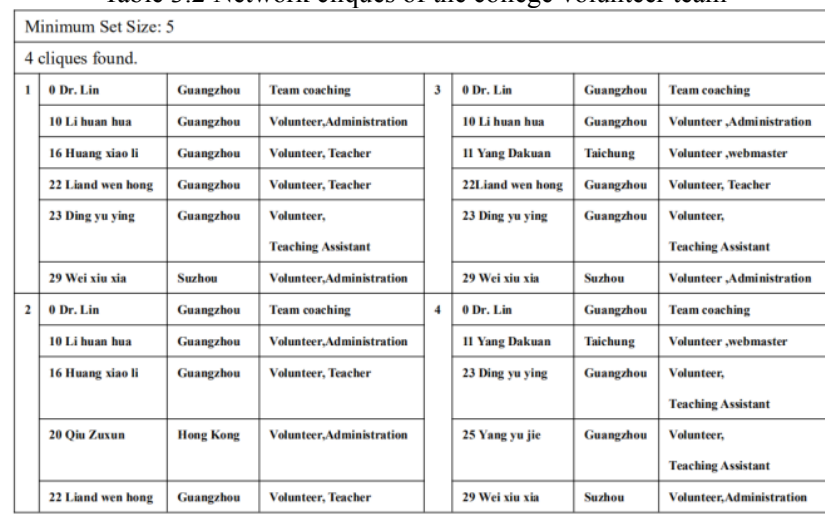

Table 3.2 about network cluster is consistent with the left side of Figure 3-6 about the relational unity of volunteers. It can be found that the collaboration of the teaching team was so intense that there were four network clusters, including the frequent mutual assistance between the persons-in-charge from the schools and between the teams, the ability to finish teaching tasks, and the performance reflecting collaboration. Such practice should be appropriately advocated. Besides, a greater play should be given to the guidance by elder fellow students to motivate more volunteers to become able to shoulder missions all by themselves. It is hoped that each network cluster will evolve into a new power center through steady improvement.

\subsection{Measurement of Action}

Despite knowledge is dispersed among many people, prices as subjective values can coordinate different people behave the same action ${ }^{[17]}$. Following this idea, we propose the price system of action. Since individual behavior is based on the principle of minimization of loss and maximization of gain ${ }^{[18]}$, price system is a metaphor for actors to measure the choices of actions. In addition, according to recommendation of Hayek, on the one hand, knowledge is the particular circumstances of 
time and place; on the other, people active cooperation guided by the understanding of price changes which depending on information gathering ${ }^{[17]}$. For individual participants taking the right action, the most significant features about information technology is the visibility. Only perfect and essential information is passed on people concerned, and then individual activities would be adjusted to fit the "price" measurement. From this we derive the following proposition:

Proposition 1: The visibility of information influences the measurement of purposive actions.

Purposive action requires information, because it is valuable behind the social structure that affects actors better to pursue their interests to seem acting the rational action ${ }^{[9]}$.

\subsection{Structuration of Collective Actions}

With the basic Giddens argument, people in interaction use the rules and resources that constitute social structure. Furthermore, referring to Giddens's "Stratification Model", the acting self involves treating the reflexive monitoring, rationalization, and motivation of action as embedded sets of processes within time-space relation. Indeed, the rationalization of action is generated within the diversity of interaction between actors. As Allen and Cohen discover the structure of technical communication patterns is both influenced on the interaction of social relations and work structure $^{[19]}$, so performance is not decided by information source itself but related in who use and apply information. However, social capital is reflected in the actual linkage between the uses of embedded assets with instrumental actions. For better accessing the embedded assess than others, individuals may intent to collective actions for the benefit of network locations leading to facilitate or prevent utilization of structural embeddeness. Therefore, we offer the following:

Proposition 2a: Structural embeddedness provides the basis for collective action to access and coordinate exchanges.

Proposition 2b: The openness of digital interaction increases the potential opportunity for structural assets.

Information technology setting regard as consideration of Lin, instrumental behaviors are equal to social interactions allowing greater social mobility and greater sharing of resources in society ${ }^{[18]}$.

\subsection{Shaping Behavior}

Walker et al. discriminate two types of network types: "closed" network and "open" network ${ }^{[20]}$. The characteristic of closed network is members are fully connected to each other so that benefits for diffusion of information; otherwise, open networks have not connected to each other extensively result in difficult to carry information on behavior in relationships. Similarly finding from Nahapiet and Ghoshal, there are many evidences support that closure as strong communities can develop high levels of relational lead to bring dense social capital $^{[21]}$. However, in contrast to Burt who describes social capital as a function of brokerage opportunities that mean weaker connections between subgroups of a network create structural holes to mediate the flow of information between group members ${ }^{[22]}$, so open network is rather than closed networks resulted from opportunities for brokering information flows.

We suppose mass collaboration on Web is a symbol of "plug and play" behavior, because the scale of informational environment where easily connects people to act in around the world. However, people usually do without anyone having to tell them what to do, so-called conscious direction ${ }^{[17]}$. While collaborative structure has been forming, rational calculation is no longer conducted by the prices system of action as unreasonable behavior. Thus, we propose the following:

Proposition 3: The scale of informational environment as normative effect shapes purposive action.

For evaluating the phenomena of mass collaboration, it is better to take notice of Lin suggestion that analyses must examine different aspects of social capital, such as information, influence, social credentials, and reinforcement among different outcomes ${ }^{[18]}$.

\section{Discussion}

Socio-economic as association-based initiatives that are based on the values of solidarity, autonomy, and citizenship contained in principle with the main purpose of services to members or the community rather than to collect profits; management is autonomous; democratic decision-making process ${ }^{[14}$, 15]. The cloud aid education embodies this concept, and civic education is the most important topic.

The summary of the data of the interviews show that cloud aid education has short-, intermediate- and long-term effects. There are two short-term effects: 1) for primary and secondary school students, it can (1) assist their study, (2) broaden their vision, (3) 
give their emotional help, and (4) change their attitude towards life and values in an unperceived way; 2) for undergraduates, it can (1) strengthen their ability to communicate with others and solve problems, (2) enhance their integrity, (3) change their attitude towards life and values in an unperceived way, and (4) provide them with job opportunities by prestigious enterprises. The intermediate effects on society are as follows: it contributes to (1) harmony, love and hope, (2) humanistic concern, and (3) the development and preservation of fine culture. The long-term effects on enterprises: it (1) improves their images, (2) reveals their social responsibilities, and (3) offers talents expected by them. The details about these effects are shown in Figure 4-1.

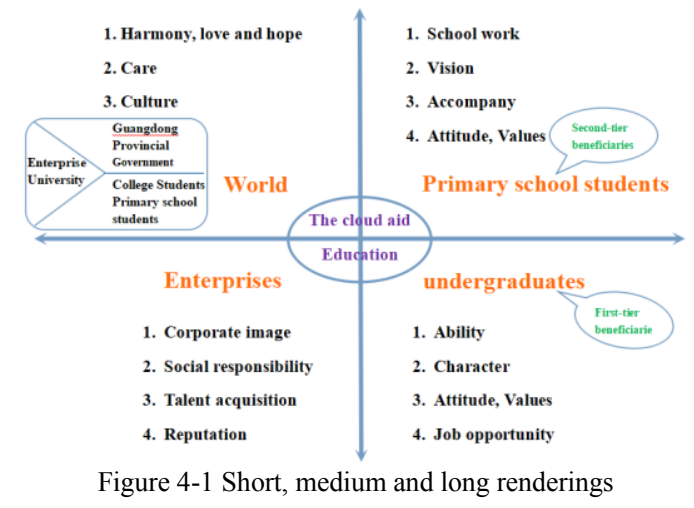

The research findings show that the college volunteer team has two remarkable organizational features in the development of cloud aid education: (1) double-layered public interests: as is revealed in the right side of Figure 5-1, the first layer is manifested in the college teachers' selfless devotion to shaping undergraduates' ability, integrity, attitude and values and their unconditional commitment; the second layer is shown in the fact that college students help and accompany primary school students, studying and growing with them, and a highly valuable goodwill loop has formed; (2) the double-loop learning in a learning-oriented organization. In offering cloud aid education, the volunteers adhere to the principle of helping target students with a good preparation. Aside from trying to meet the lecture requirements in the preparation, they have discussions and rehearsals with their partners in the teaching team and share

Overall, there are both conceptual and methodological issues involved in this study. First, the theoretical exposition adopted research framework guides the basic analysis approach. Second, an experiment within mass collaboration project to generate important factors inhere the dynamic collaborative network.

In this research-in-progress, we are going to adopt an empirical practice for The cloud aid education. Through The cloud aid education, people work on related tasks making it easier for participators to develop stable cooperative relationships. Figallo and Rhine (2002) propose that online interfaces can bring more specific interest groups to share a variety of resources together in one place ${ }^{[23]}$. For proving the significance of interrelationships of actor, action, structure, and information technology, we divide near 3,000 volunteers into experiment and control groups. Thus, we can compare two groups in manipulating information technology as moderate factors between entities and entire relationship of ongoing network structure.

According to the data collection of network study, individuals are required to ask by a series interrelate of factors to put a checkmark to every person about whom they have contact, how often they have contact and the substance of interactions. Following the interview requirements of Social Action Research (SAR), the path for team members to interact with each other is the blueprint for accomplishing tasks. Understand the objects, conditions and frequency of interaction during task execution. The experimental procedures of this study are designed into three steps. At the beginning, we use above questionnaire to investigate relationship matrix for all participators in the PPGIS program, and then aggregate to sociogram that visually displays the relationships between all nodes and ties in a network; Secondly, same behaviors appear more often due to other actors learning from it based on a more or less informed process, so for experiment group, we make more durable and more frequent interactions between group members by sharing amount of information and feedback for a long time in contrast to control group; Finally, we repeat the examination introduced in first step to measure the sociogram in different groups again, and then compare network structure separately.

This study is based on social network analysis, namely size, density, degree centrality, network centrality, clique membership and factions. The social network analysis has been used to sociological studies in attributes of individual actors, relationship of each entities, connection style of ties, and structure patterns of network. The purpose of this work is to verify the research framework through an online free collaborative system. The cloud aid education show social network of participators' interaction correlated to social mechanisms. Furthermore, the reflexive monitoring of action in situations concurrently is the main anchoring feature of social integration. 
Because it is part of the formal primary school curriculum, not extracurricular interest teaching, the school supervisor will have formal teaching evaluation feedback after each class, and it does track the quality of teaching so that both teaching and learning can improve at any time.

To analyze the factors of mass collaboration in this way is to elucidate axis of structuration connecting the participation in the PPGIS program with broader aspects of the social influences involving the transformation and mediation relation implicated in the reflexive monitoring processes across space and time.

\section{Conclusion}

The "price" conditions affected various persons to action and this collective action given the existing structure of relations, combined to produce the system of action that resulted in community action. As popularization of the Web, it obviously changes the way of sharing information and communication lead to change the behavior of people and interaction with one another. Collaboration is defined as a group of people striving towards a common goal. For this group, being social isn't about sharing who they are; it's about sharing what they do and how they do it. In other words, being social means coming together to achieve a common end.

This study provides a theoretical framework that interdependent individual actions lead to the social structure and in turn shape motivation and effort in collaboration for exploring the mechanics of modern mass collaboration. First, the article presents a summary of rational behavior theory and a set of relative social network theories. Following is an analysis of research framework that relates purposive action with social network theories and allied with moderation of information technology. The study concludes with the applicability of the analytical concepts and assumptions of economical and sociological approach to explore the theory of mass collaboration, and the potential for such work to generate further theory.

The cloud aid education promoted by the college volunteer team is noticeably effective in promoting equitable education opportunities. All Chinese universities have their own partner county or city to which they would offer poverty alleviation services. This study suggests that cloud aid education be added to their poverty reduction programs to give priority to the educational development of these counties and cities, which will have far-reaching effects on the human resource structures of the economically-underdeveloped regions. Moreover, the educational administration departments should take initiative to form a union among local universities to achieve more achievable management, institution and rewards of cloud aid education. This is also a great incentive for college volunteers. Last but not least, enterprises should give more support for the subscription of the classrooms of cloud aid education and donate them to the primary schools which need these classrooms. The cloud aid education is an organization of college students, and funding is very difficult, so they launched a purchase instead of donation activity to promote the adoption of love classes and help fund raising. By doing so, they not only can benefit primary and secondary school students and undergraduates but also fulfill their social responsibilities and improve their images. Ritesh Chugh study demonstrates that giving took a social network effect and people donated as they felt connected to the cause, even from a geographically distant location ${ }^{[16]}$. This will be the next direction that the cloud aid education needs to work on.

The cloud aid education is not only promoted in China, but has recently negotiated with Kyrgyzstan in Central Asia on entrepreneurial teaching and Mandarin teaching plans to promote the cloud aid education results to other countries.

The research on the social network and mass collaboration focuses on business models and interests. Emphasis is placed on the discussion of economic value. In addition to the sense of mission of a charity organization, the cloud aid education also integrates the performance of business operations, which is the integration of social and economic values. Seek a balance between mission and the market, and reinvest the income in mission activities or pay for operating expenses, so that the promotion of public welfare projects can be sustainable. This paper supplements some of the gaps in the social network and mass collaboration research. Taking non-profit organizations as the research object, the quantifiable performance of volunteer services is not obvious. The results are intangible and difficult to quantify value. It is difficult to capture in terms of human interaction, collaboration, and mutual care and trust. This study uses social network analysis to fully grasp key people and further understand their impact on the organization. Compared with general business organizations, there are different values and operating modes that are worth learning.

The future research on this subject can be started from (1) study and observe the social network and mass collaboration research of the overall operation of the 
hybrid structure of the cloud aid education. After all, the operation of the hybrid structure is more diverse, more complex, and more difficult. (2) study and observe the cross-border operation performance of the cloud aid education. In the promotion process of different countries, they will encounter language, customs and cultural shocks. As the scale of collaboration expands, the difficulty will also double. Whether the cloud aid education experience in China can overcome obstacles is worthy of attention.

\section{Acknowledgement}

This research was support by following funds which we thanks for. And the authors would take all responsibility for this paper.

1.Department of Education of Guangdong Province "Innovative projects with characteristics of ordinary universities" project: Research on Sustainable Development of Foreign Trade in Guangdong Province Based on Emergy Footprint (Project Number: 2019WTSCX158 )

2.Huashang College Guangdong University of Finance and Economic Province: Research on the Transformation and Upgrading of Chinese Private Family Enterprises(Project Number: 2019HSDSo6)

3.Humanities and Social Sciences Research Projects of Universities in Guangdong Province: (Project Number: 2015WTSCX126 )

\section{References:}

[1] Xie Rong. Study on Provincial Equity of Basic Public Educational Resources Allocation[J]. Education Science. 2012, 28(6): 18-22.

[2] Coleman J S. Social capital in the creation of human capital[J]. American journal of sociology. 1988, 94: S95S120.

[3] Wellman B, Berkowitz S D. Social structures: A network approach[Z]. CUP Archive, 1988: 2.

[4] Agarwal R, Gupta A K, Kraut R. Editorial overview - The interplay between digital and social networks[Z]. INFORMS, 2008.

[5] Tapscott D, Williams A D. Wikinomics: how mass collaboration changes everything,[Z]. New York: Penguin Group., 2006.

[6] Scacchi W. Free/open source software development: recent research results and emerging opportunities[Z]. 2007459-468.

[7] Granovetter M. Economic action and social structure: The problem of embeddedness[J]. American journal of sociology. 1985, 91(3): 481-510.

[8] Maznevski M L, Chudoba K M. Bridging space over time: Global virtual team dynamics and effectiveness[J]. Organization science. 2000, 11(5): 473-492.

[9] Coleman J S. Social theory, social research, and a theory of action[J]. American journal of Sociology. 1986, 91(6): 1309-1335.

[10] Urry J. Small worlds and the new 'social physics'
[J]. Global networks. 2004, 4(2): 109-130.

[11] Thaler R H, Sunstein C R. Nudge: improving decisions about health, wealth, and happiness[Z]. HeinOnline, 2009.

[12] Hall H. Borrowed theory: applying exchange theories in information science research[J]. Library \& Information Science Research. 2003, 25(3): 287-306.

[13] Hanneman R, Riddle. M. Introduction to social network methods. [Z]. Riverside, CA: University of California (published in digital form at http://faculty.ucr.edu/ hanneman/), 2005.

[14] Irina Gontareva, Borovyk Maryna, Vitalina Babenko, et al. Identification of Efficiency Factors for Control over Information and Communication Provision of Sustainable Development in Higher Education Institutions[J]. WSEAS Transactions on Environment and Development. 2019(Volume 15): 593-604.

[15] Nurhayati A, Aisyah I, Supriatna A K. The Relevance of Socioeconomic Dimensions in Management and Governance of Sea Ranching[J]. WSEAS Transactions on Environment and Development. 2019, 15(2019): 78-88.

[16] Chugh R. Disaster Fundraising via Social Media: A Case Study of Non-resident Nepalese Community in Australia[J]. WSEAS Transactions on Environment and Development. 2018(Volume 14): 636-642.

[17] Hayek F A. The use of knowledge in society[J]. The American economic review. 1945, 35(4): 519-530.

[18] Lin N. Social capital: A theory of social structure and action[Z]. Cambridge university press, 2002: 19.

[19] Allen T J, Cohen S I. Information flow in research and development laboratories[J]. Administrative science quarterly. 1969: 12-19.

[20] Walker G, Kogut B, Shan W. Social capital, structural holes and the formation of an industry network[J]. Organization science. 1997, 8(2): 109-125.

[21] Nahapiet J, Ghoshal S. Social capital, intellectual capital, and the organizational advantage[J]. Academy of management review. 1998, 23(2): 242-266.

[22] Burt R S. A note on social capital and network content[J]. Social networks. 1997, 19(4): 355-373.

[23] Figallo C, Rhine N. Building the knowledge management network: Best practices, tools, and techniques for putting conversation to work[Z]. John Wiley \& Sons, 2002.

Creative Commons Attribution License 4.0 (Attribution 4.0 International, CC BY 4.0)

This article is published under the terms of the Creative Commons Attribution License 4.0 https://creativecommons.org/licenses/by/4.0/deed.en US 